\title{
Model of Fungal Development in Stored Barley Ecosystems as a Prognostic Auxiliary Tool for Postharvest Preservation Systems
}

\author{
Jolanta Wawrzyniak ${ }^{1}$ (D)
}

Received: 27 May 2020 / Accepted: 21 December 2020 / Published online: 9 January 2021

(C) The Author(s) 2021

\begin{abstract}
Postharvest preservation and storage have a crucial impact on the technological quality and safety of grain. The important threat to stored grain quality and nutritional safety of cereal products is mould development and their toxic metabolites, mycotoxins. Models based on predictive microbiology, which are able to estimate the kinetics of fungal growth, and thus, the risks of mycotoxin accumulation in a mass of grain are promising prognostic tools that can be applied in postharvest management systems. The study developed a modelling approach to describe total fungal growth in barley ecosystems stored at different temperatures $\left(T=12-30^{\circ} \mathrm{C}\right)$ and water activity in grain $\left(a_{\mathrm{w}}=0.78-0.96\right)$. As the pattern of fungal growth curves was sigmoidal, the experimental data were modelled using the modified Gompertz equation, in which constant coefficients reflecting biological parameters of mould development (i.e. lag phase duration $\left(\tau_{\text {lag }}\right)$, maximum growth rate $\left(\mu_{\max }\right)$ and the maximum increase in fungal population level $\left(\Delta_{\max } \log (\mathrm{CFU})\right)$ were expressed as functions of storage conditions, i.e. $a_{\mathrm{w}}$ and $T$. The criteria used to evaluate the overall model performance indicated its good precision $\left(R^{2}=0.95\right.$; RMSE $\left.=0.23\right)$ and high prediction accuracy (bias factor and accuracy factor $B_{\mathrm{f}}=1.004, A_{\mathrm{f}}=1.035$ ). The formulated model is able to estimate the extension of fungal contamination in a bulk of grain versus time by monitoring temperature and intergranular relative humidity that are readily measurable in practice parameters; therefore, it may be used as a prognostic support tool in modern postharvest management systems.
\end{abstract}

Keywords Grain storage $\cdot$ Mould population $\cdot$ Fungal development $\cdot$ Predictive model $\cdot$ Mould growth prediction $\cdot$ Food mycology

\section{Introduction}

Postharvest preservation and storage treatments have a crucial impact on the technological quality and safety of cereal grain. One of the important threats to grain quality and thus also to the nutritional safety of cereal products is the presence of fungal propagules (spores, sclerotium, fragments of mycelia) in stored grain ecosystems. Fungi can penetrate into grain during plant growth, transport or postharvest processes. They are able to develop in a wide range of water availability and temperature levels; moreover, under conditions conductive to their development they can grow rapidly, even if the grain is initially contaminated with a small amount of fungal

Jolanta Wawrzyniak

jolanta.wawrzyniak@up.poznan.pl

1 Food Engineering Group, Department of Technology of Plant Origin Food, Poznań University of Life Sciences, ul. Wojska Polskiego 31, 60-624 Poznan, Poland inoculum (Mankevičienè et al. 2019). Improperly conducted postharvest management can not only cause mould expansion leading to undesirable changes in grain quality (Magan et al. 2003), but also can result in the appearance of fungal toxic metabolites (mycotoxins), which constitute a considerable risk to animal and human health. It is worth noting that mycotoxins once accumulated are inherently impossible to remove from the mass of grain (Bullerman and Bianchini 2007; Kochiieru et al. 2019).

In recent years, much research has been conducted in order to develop new methods for a rapid and reliable detection of fungal infections. The near-infrared (NIR) spectroscopy has been proposed for the detection of different stages of fungal infection in cereal grain (Orina et al. 2017). Gancarz et al. (2017) and Rusinek et al. (2019) tested the use of an e-nose as a tool for quick assessment of the degree of mould contamination in stored oilseeds. Despite the considerable efforts made, we still lack universal, simple and rapid methods to assess grain contamination with fungi. Apart from that existing methods perceive the signs of fungal activity that 
has already occurred, whereas for postharvest grain preservation systems, prediction of the risk associated with the mould development, before it appears, seems to be a much better solution. Although, there is no a direct correlation between mould growth and mycotoxin production, preventing fungal growth in raw materials and food invariably leads to the prevention of the presence of mycotoxins (Garcia et al. 2009). Rapid risk assessment that allows the manufacturer to take appropriate steps to protect mass of grain from mould development is particularly important when drying is carried out under mild temperature conditions, i.e. the near-ambient drying in static deep beds. This drying method is especially dedicated to grain that should be characterized by high biological activity, i.e. malting barley that is needed to maintain high germinability and germination energy of grain, the key parameters in malt production. The near-ambient drying has many advantages; however, it is a long-lasting process and, in the climate that is a mixture of maritime and temperate climates (as in most Central and Northern European countries), may take from 1 to 3 weeks (Gawrysiak-Witulska et al. 2008; Ryniecki et al. 2007). During drying time, moisture can migrate from warmer parts of grain (in the sunlit southern side of the silo) to colder ones (in the northern side of the silo), causing grain rewetting. This carries the risk of mould growth and grain quality deterioration. For this reason, it is urgent to search for new tools to estimate the risk of fungal development and thus mycotoxin formation in a bulk of grain.

Predictive microbiology is a promising approach in the estimation of fungal grain contamination and the risk of mycotoxin accumulation. In recent years, it has focused mainly on food-pathogenic bacteria and modelling of fungal growth has received much less attention (Dantigny 2016). Research on prognostic tools for fungal growth prediction demands numerous labour-intensive experiments, conducted in systems as close as possible to actual ones, the purpose of which is to provide a large amount of raw data associated with the kinetics of mould growth and mycotoxin formation in a wide range of environmental conditions. In previous studies, data describing kinetics of mould development were usually obtained for fungi growing on agar media on petri dishes (Aldars-García et al. 2017; Marín et al. 2009; Pardo et al. 2004), with the colony diameter used to measure the intensity of mould growth (Jacxsens et al. 2016; Yogendrarajah et al. 2016). In such experiments, the mycelia usually originated from singlepoint inoculation with a high number of fungal spores (Marín et al. 2009; Panagou et al. 2010; Pardo et al. 2004), whereas in the case of the bulk of harvested grain, fungal spores are not concentrated in one place, but are spread stochastically in its entire mass. Moreover, the measurement of colony diameter on petri dishes does not represent the true tridimensional fungal growth (Garcia et al. 2009). The main limitation of the abovementioned method is the fact that it cannot be applied in food analysis, as it focuses on visible growth, whilst for food manufacturers, the knowledge of the activity of food spoilage microorganisms at the earliest stage of its development is more valuable (Garcia et al. 2009; Vindeløv and Arneborg 2002). Saxena et al. (2001) examined the relationships of ergosterol levels, total viable mould count and ochratoxin A production of Aspergillus ochraceus and Penicillium verrucosum and showed that the viable mould count, expressed in colony forming units (CFU) per gram of grain $\left(\mathrm{cfu} \mathrm{g}^{-1}\right)$, makes it possible to detect mould growth and thus the risk of OTA formation sooner than ergosterol used as an indicator of fungal biomass. Garcia et al. (2009) and Dantigny (2016) indicated that CFU counts applied to moulds take into account mostly spore numbers; nevertheless, it should be emphasized that it is mould spores occurring in freshly harvested grain that under favourable conditions become the source of numerous outbreaks of fungal infestation in the stored mass of grain.

To evaluate the risk of mould growth, various experimental designs and predictive models were applied (Aldars-García et al. 2017; Jacxsens et al. 2016; Marín et al. 2009; Pardo et al. 2004; Samapundo et al. 2005; Yogendrarajah et al. 2016). Nevertheless, in those considerations, model parameters were usually determined for the individual fungal species growing under idealized laboratory conditions. The importance of interactions between organisms and their effects on spore germination, growth and production of metabolites has often been disregarded (Dantigny 2016). As a consequence, observations for individual species do not always overlap with those in natural ecosystems (Magan and Aldred 2007; Mylona and Magan 2011). When the kinetics parameters of mould growth are determined in an arbitrarily modified experimental system (far from the real one), the obtained models may not accurately reflect fungal growth under actual conditions.

There is a lack of modelling studies for the growth of fungal mycobiota in a mass of grain predicting the level of viable mould count as a function of temperature and water activity, which could be used for a bulk of grain treated as a holistic system in postharvest management. Therefore, the aim of this study was to develop a modelling approach to predict the kinetic of mould growth in a stored bulk of barley grain, as a function of water activity, temperature and time. To ensure safety during the model application, it was formulated on the basis of data reflecting bulks of grain with a hazardous initial fungal propagules typical of years with high rainfall during the vegetation and harvest periods.

\section{Materials and Methods}

\section{Data Sets}

The raw data associated with the level of mould grain contamination were obtained from experiments described previously 
by Wawrzyniak et al. (2018a). To enhance clarity of this manuscript, the materials and methods for this study are shortly described here.

\section{Grain Preparation and Experiment Design}

Before the experiments, grain samples of barley cv. Sebastian with a moisture content (MC) of $127.0 \pm$ $0.8 \mathrm{~g} \mathrm{~kg}^{-1}$ wet basis (w.b.) and the fungal infestation of $(2.9 \pm 0.9) \times 10^{4} \mathrm{cfu} \mathrm{g}^{-1}$ were adjusted to the assumed storage conditions according to the previous report (Wawrzyniak et al. 2018a). The adjustment was carried out in order to simulate the natural ecosystems of grain with a hazardous initial microbiological state characteristic of grain that vegetated or was harvested under adverse weather conditions. For this purpose, grain was wetted to a $\mathrm{MC}$ being consistent with the adequate relative humidity at the equilibrium state in intergranular spaces (where $\mathrm{ERH}=100 \cdot a_{\mathrm{w}} \%$ and $a_{\mathrm{w}}$ is water activity in grain) at a given temperature $(T)$. The applied storage temperatures and water activities in grain were presented in Table 1. As the presence of mycotoxins in stored grain is mainly related to the activity of toxigenic fungal genera of Aspergillus and Penicillium (Cabañes et al. 2010; Magan 2006; Medina et al. 2017; Wawrzyniak and Waśkiewicz 2014), grain naturally contaminated with moulds after wetting was additionally inoculated with a mixture of spores of two toxigenic fungal strains, i.e. A. ochraceus Wilhelm (KKP 439) and P. verrucosum (formerly classified as Penicillium viridicatum Westling), (KKP 480) (Cabañes et al. 2010; Pitt 1987) obtained from the Collection of Industrial Microorganisms (IAFB 212), Institute of Agricultural and Food Biotechnology in Warsaw, Poland, which are representative of storage mycobiota, commonly

Table 1 Storage conditions, temperature and water activity in grain $\left(a_{\mathrm{w}}\right)$ applied in storage experiments that were used to model development and validation

\begin{tabular}{lll}
\hline Temperature & Model development & Model validation \\
\hline$\left({ }^{\circ} \mathrm{C}\right)$ & $a_{\mathrm{w}}$ & $a_{\mathrm{w}}$ \\
12 & 0.89 & 0.86 \\
& 0.96 & \\
18 & 0.85 & 0.91 \\
& 0.95 & \\
24 & 0.81 & 0.85 \\
& 0.91 & \\
& 0.93 & 0.84 \\
30 & 0.78 & \\
& 0.80 & \\
\hline
\end{tabular}

found in regions with the mixture of maritime and temperate climates (JECFA 2002; Lund and Frisvad 2003). Inoculation suspensions and samples of inoculated barley grain were prepared according to procedure described previously by Wawrzyniak et al. (2013). The total spore count of each inoculation suspension amounted to $(3.1 \pm 0.8) \times$ $10^{7}$ spores $\mathrm{ml}^{-1}$ for $A$. ochraceus and $(2.5 \pm 0.9) \times 10^{7}$ spores $\mathrm{ml}^{-1}$ for $P$. verrucosum. As a result, at the beginning of the experiments, the average total level of fungal propagules was $4.4 \times 10^{4} \mathrm{cfu} \mathrm{g}^{-1}$ of grain, and it reflected the level of fungi population found in grain ripening and harvested in years rich in precipitation (Akk et al. 2013).

Wetted and inoculated grain was stored in the environmental chamber under stable temperature and water activity conditions (monitored online using thermocouples and humidity probes), as described previously by Wawrzyniak et al. (2013). The constant level of water activity in grain, which at the equilibrium state is equivalent to relative humidity in intergranular spaces, was maintained using saturated salt solutions. All experiments were repeated twice, and their duration (40-60 days) depended on storage conditions. Throughout storage the level of fungal contamination expressed as CFU of moulds ( $\mathrm{cfu} \mathrm{g}^{-1}$ ) was determined (in three repetitions) with different frequencies depending on the applied values of $T$ and $a_{\mathrm{w}}$ in grain using the plate method performed in accordance with PN-ISO 21527-2:2009 and EN-ISO 6887-1:2000 standards. The procedure of microbiological analysis of grain was described in detail by Wawrzyniak et al. (2018a).

\section{Data Treatment}

The decimal logarithm of mean values of CFU of mould $\left(\log (\mathrm{CFU}), \log \left(\mathrm{cfu}^{-1}\right)\right)$, describing the fungal population in grain was used to develop the model. The experimental data was divided into two groups; one was used to develop the model of mould growth, whilst the other was used to its validation (Table 1). Whilst modelling, it was assumed that through the whole lag-phase of fungal growth, the CFU of mould was equalled to the initial one.

\section{Modelling of Mould Growth}

A two-step approach comprising of formulation of primary models and then the elaboration of an overall predictive model was used to describe mould growth in a bulk of barley grain.

\section{Mould Growth under Steady Environmental Conditions-Primary Models}

Estimation of the fungal population level in relation to time under steady environmental conditions is known as primary 
modelling. One of several sigmoidal functions recommended to describe growth curves is the modified Gompertz equation (Zwietering et al. 1990) of the general form:

$y=a \cdot \exp [-\exp (b-c \cdot x)]$

in which coefficients $(a, b, c)$ are linked with biological parameters characterizing the dynamics of fungal growth as follows:

$a=\Delta_{\max } \log (\mathrm{CFU})$

$b=\frac{\mu_{\max } \cdot e}{\Delta_{\max } \log (\mathrm{CFU})} \cdot \tau_{\text {lag }}+1$

$c=\frac{\mu_{\max } \cdot e}{\Delta_{\max } \log (\mathrm{CFU})}$

where $\Delta_{\max } \log (\mathrm{CFU})$ is the maximum increase in fungal population from the initial level $\log \left(\mathrm{CFU}_{0}\right)$ to that at the stationary phase $\log \left(\mathrm{CFU}_{\mathrm{s}}\right),\left(\log \left(\mathrm{cfu} \mathrm{g}^{-1}\right)\right) ; \mu_{\max }$ is defined as maximum growth rate in $\log (\mathrm{CFU}),\left(\log \left(\mathrm{cfu} \mathrm{g}^{-1}\right) \mathrm{d}^{-1}\right)$; and $\tau_{\text {lag }}$ is lag phase duration (d). As a result, the general form of primary models of mould growth $\left(\mathrm{PM}_{\mathrm{MG}}\right)$ in a bulk of barley grain stored under steady environmental conditions took the following form:

$$
\begin{aligned}
\log (\mathrm{CFU}) & =\log \left(\mathrm{CFU}_{0}\right)+\Delta_{\max } \log (\mathrm{CFU}) \\
& \cdot \exp \left[-\exp \left(\frac{\mu_{\max } \cdot e}{\Delta_{\max } \log (\mathrm{CFU})} \cdot\left\{\tau_{\mathrm{lag}}-\tau_{\mathrm{CFU}}\right\}+1\right)\right]
\end{aligned}
$$

where $\tau_{\mathrm{CFU}}$, time, after which the fungal population reaches the level of $\log (\mathrm{CFU}),(\mathrm{d}) ; \mathrm{e}=\exp (1)$. The values of biological parameters for each set of $\mathrm{T}$ and $\mathrm{a}_{\mathrm{w}}$ in grain were estimated with the use of nonlinear regression by fitting the obtained equation to the experimental data at the $95 \%$ confidence level. Nonlinear regressions were performed using the STATISTICA 13 software package (StatSoft, Inc., Tulsa, OK, USA).

\section{Model of Mould Growth as a Function of Temperature and Water Activity}

During further modelling, the effect of temperature and water activity in grain on the kinetic parameters of mould growth was taken into account. For this purpose, the relation between $\mu_{\max }, \log \left(\mathrm{CFU}_{\mathrm{s}}\right), \tau_{\text {lag }}$ and $a_{\mathrm{w}}$ and $T$ was studied to find mathematical expressions describing a dependence between the abovementioned parameters and storage factors. The first-order polynomial function provided a satisfactory description of the influence of $a_{\mathrm{w}}$ and $T$ on each of the parameters:

$$
\begin{aligned}
& \log \left(\mathrm{CFU}_{\mathrm{s}}\right)=s_{0}+s_{1} \cdot t+s_{2} \cdot a_{\mathrm{w}} \\
& \mu_{\text {max }}=m_{0}+m_{1} \cdot t+m_{2} \cdot a_{\mathrm{w}} \\
& \tau_{\text {lag }}=l_{0}+l_{1} \cdot t+l_{2} \cdot a_{\mathrm{w}}
\end{aligned}
$$

where $s_{i}, m_{i}$ and $l_{i}$ are coefficients of these functions.

Replacing the constant biological parameters of mould growth in the general form of $\mathrm{PM}_{\mathrm{MG}}$ (Eq. (5)) with functions describing their dependence on storage conditions enabled to developed the overall predictive model of mould growth $\left(\mathrm{OPM}_{\mathrm{MG}}\right)$ in the stored grain ecosystems as a function of temperature, water activity in grain and time. As a consequence, the overall model took the following form:

$$
\begin{gathered}
\log \left(\mathrm{CFU}_{\mathrm{M}}\right)=\log \left(\mathrm{CFU}_{0}\right)+\left(\left(s_{0}+s_{1} \cdot t+s_{2} \cdot a_{\mathrm{w}}\right)-\log \left(\mathrm{CFU}_{0}\right)\right) \\
\cdot \exp \left[-\exp \left(\frac{\left(m_{0}+m_{1} \cdot t+m_{2} \cdot a_{\mathrm{w}}\right) \cdot e}{\left(\left(s_{0}+s_{1} \cdot t+s_{2} \cdot a_{\mathrm{w}}\right)-\log \left(\mathrm{CFU}_{0}\right)\right)}\left\{\left(l_{0}+l_{1} \cdot t+l_{2} \cdot a_{\mathrm{w}}\right)-\tau_{\mathrm{CFU}}\right\}+1\right)\right]
\end{gathered}
$$

The coefficients of the $\mathrm{OPM}_{\mathrm{MG}}$ were estimated by fitting the formulated model equation (Eq. (8)) to the experimental data selected to model development (Table 1) using nonlinear estimation of the STATISTICA 13 (StatSoft, Inc., Tulsa, OK, USA) at the $95 \%$ confidence level. The assumed initial level of $\log \left(\mathrm{CFU}_{0}\right)$ in the predictive model was $4.4 \log \left(\mathrm{cfu} \mathrm{g}^{-1}\right)$, and it was the average level of $\log (\mathrm{CFU})$ of mould population applied at the beginning of all storage experiments.

\section{Models Performance Evaluation}

The goodness-of-fit of the obtained models ( $\mathrm{PM}_{\mathrm{MG}}$ and $\mathrm{OPM}_{\mathrm{MG}}$ ) to experimental data was evaluated using the determination coefficient $\left(R^{2}\right)$ and the root mean square error (RMSE) being the measure of the closeness of the predicted values $\left(\log \left(\mathrm{CFU}_{\mathrm{M}}\right)\right)$ to the experimental data $\left(\log \left(\mathrm{CFU}_{\mathrm{E}}\right)\right)$ expressed as follows:

$\operatorname{RMSE}=\sqrt{\frac{\sum\left(\log \left(\mathrm{CFU}_{\mathrm{E}}\right)-\log \left(\mathrm{CFU}_{\mathrm{M}}\right)\right)^{2}}{n-p_{\mathrm{M}}}}$

where $n$ is the number of observations and $p_{\mathrm{M}}$ is the number of model parameters. The closer the RMSE value is to zero, the better model fit to the experimental data.

The prognostic reliability of the overall predictive model of mould growth was evaluated in two steps as described by Te 
Giffel and Zwietering (1999): internal validation (on the basis of the same data as the model was developed) and external validation (on the basis of data from four independent experiments) of the OPM $\mathrm{MG}_{\mathrm{MG}}$ using two indicators dedicated to validation of predictive models (Te Giffel and Zwietering 1999; Walther and Moore 2005). The average difference between the predicted and experimental values was described with a bias factor $\left(\mathrm{B}_{\mathrm{f}}\right)$, which informs whether the predicted values are overestimated or underestimated in relation to the experimental values, and it was calculated as follows:

$B_{\mathrm{f}}=10\left(\sum \log \left(\frac{\log \left(\mathrm{CFU}_{\mathrm{M}}\right)}{\log \left(\mathrm{CFU}_{\mathrm{E}}\right)}\right) / n\right)$

When a bias factor equals 1 , it means that there is no structural deviation and that the positive and negative deviations of the model are on average equal to each other. A bias factor $<1$ indicates that the values predicted with the model are underestimated, whilst a bias factor $>1$ indicates that the model has the tendency to overestimate the predicted values (Te Giffel and Zwietering 1999). The overall distance between estimated and experimental values was defined with an accuracy factor $\left(A_{\mathrm{f}}\right)$ calculated using the following equation:

$A_{\mathrm{f}}=10\left(\sum\left|\log \left(\frac{\log \left(\mathrm{CFU}_{\mathrm{M}}\right)}{\log \left(\mathrm{CFU}_{\mathrm{E}}\right)}\right)\right| / n\right)$

The values of $A_{\mathrm{f}}$ close to 1 indicate a low percentage of error in the model prediction and thus high accuracy of the model.

\section{Results and Discussion}

\section{Modelled Data and the Pattern of Growth Curves}

Since modelling approach can forecast changes of microbial populations exposed to specific conditions it may be utilized in planning Hazard Analysis and Critical Control Points (HACCP) programs (Gil et al. 2017).

Predictions may help to identify parameters, which could be modified in existing technological processes or postharvest crop management strategy in order to prevent the development of undesirable microorganisms and attain high-quality food. Nevertheless, for this purpose, relevant wide ranged data gained in experiments carried out in systems as close as possible to real-life farm conditions are required. In previous studies, modelling of mould growth was based on data obtained on agar-based or previously disinfected food media, where the intensity of visible individual mould expansion was usually measured by colony diameter (Aldars-García et al. 2017; Jacxsens et al. 2016; Marín et al. 2009; Tremarin et al. 2017; Yogendrarajah et al. 2016). Models developed with the use of data obtained for single strain in an arbitrarily modified experimental system may not accurately reflect fungal growth under actual conditions (Garcia et al. 2009; Magan and Aldred 2007; Mylona and Magan 2011). From the point of view of cereal storage, models dedicated to postharvest systems should not only be based on data reflecting real grain ecosystems, but also should be capable to predict the fungal activity at the earliest stage of its development before the visible growth and the risk of mycotoxin formation occur; therefore, this study presents the modelling approach based on mould growth data expressed in colony-forming units reflecting the fungal activity in a mass of grain at early stage of their development. The modelled data were collected in 16 long-term storage experiments covering a wide range of water activity $\left(a_{\mathrm{w}}=0.78-0.96\right)$ and temperature $\left(T=12-30{ }^{\circ} \mathrm{C}\right)$. During these experiments, changes in fungal population levels and mycotoxin accumulation were investigated in barley grain ecosystems, which were reported in the study on the dynamics of fungi growth in a bulk of barley grain (Wawrzyniak et al. 2018a).

The mentioned study showed that at the beginning of the trials, the moulds identified in barley grain included fungi of the genera Fusarium, Cladosporium, Alternaria, Acremonium and Ulocladium and occasionally storage fungi such as Aspergillus and Penicillium. In the course of the experiments, field moulds was gradually replaced by storage fungi, and finally in grain with higher $a_{\mathrm{w}}$ at 12 and $18{ }^{\circ} \mathrm{C}$, mostly Penicillium spp. and less A. ochraceus Wilhelm occurred, whilst at 24 and $30{ }^{\circ} \mathrm{C}$, Aspergillus candidus Link prevailed alongside less numerous Aspergillus glaucus group, Aspergillus versicolor (Vuill.) Tiraboschi, and even fewer numerous Penicillium spp. Barley ecosystems with lower $a_{\mathrm{w}}$ stored at 12 and $18{ }^{\circ} \mathrm{C}$ were inhabited mainly by A. ochraceus, A. glaucus group, Aspergillus flavus Link and Penicillium spp., whilst at 24 and $30{ }^{\circ} \mathrm{C}$, by $A$. versicolor, A. candidus and A. glaucus group.

Most fungal growth curves, obtained in the experiments, exhibited three, typical for microbial growth stages, covering the lag-phase followed by the exponential phase and a stationary phase. The exception was ecosystems with a low $a_{\mathrm{w}}=$ 0.80 stored at $12-18{ }^{\circ} \mathrm{C}$, in which fungal development was significantly limited and encompassed only the first phase of growth, i.e. lag phase. As it is preferable to restrict log-logistic model fitting to experimental datasets showing a clear sigmoidal shape (Serment-Moreno et al. 2016), the data from the experiments carried out in barley ecosystems with $a_{\mathrm{w}}=0.80$ stored at $12-18^{\circ} \mathrm{C}$ were omitted in further research, and only full growth curves (containing the three phases of fungal development) were used to formulate the predictive model of mould growth in a bulk of barley grain. The omission of the data is not relevant to the safety of the model application due to the fact that under mentioned conditions there is the low risk of mould development, and their toxic metabolite accumulation, as the fungal growth and mycotoxins formation in 
grain with $a_{\mathrm{w}} \leq 0.80$ stored at $12-18{ }^{\circ} \mathrm{C}$, is almost completely restricted (Cairns-Fuller et al. 2005; Lindblad et al. 2004; Pardo et al. 2004; Wawrzyniak et al. 2018b).

\section{Modelling of Mould Growth}

\section{Primary Models of Mould Growth under Steady Environmental Conditions}

In prognostic microbiology several mathematical functions are used to describe the kinetics of microbial behaviour following a sigmoidal pattern (Wang et al. 2013). In many research works, these equations are adopted to quantify bacterial pathogen's growth inhibition under specific environmental conditions (Char et al. 2010; Gupta et al. 2012; Liplap et al. 2014; Serment-Moreno et al. 2015; Valdivia-Nájar et al. 2017). Zwietering et al. (1990) modelling bacterial growth found that among tested functions, the three-parameter modified Gompertz equation proved to be the most satisfactory. The advantage of the modified Gompertz equation stems from its simplicity and the fact that its parameters can be given a biological meaning. In the study, the modified Gompertz equation was used to formulate the primary models describing the growth of total fungal population in barley grain stored under various steady humidity and temperature conditions. The kinetic parameters of the $\mathrm{PM}_{\mathrm{MG}}$ (i.e. lag phase duration $\left(\tau_{\text {lag }}\right)$, maximum growth rate $\left(\mu_{\max }\right)$ and the maximum increase in fungal population level $\left(\Delta_{\max } \log (\mathrm{CFU})\right)$ were determined independently for each set of storage conditions by fitting the modified Gompertz equation to growth curves, and its values together with the statistical indices evaluating performance of the formulated primary models are listed in Table 2. The $R^{2}$ between 0.98 and 1.00 , and the values of deviation (RMSE) ranging between 0.05 and 0.16 indicate that the models represented more than $98 \%$ of the observed variability and accurately described the experimental data. Similar values of $R^{2}(0.98-1.00)$ and RMES (0.15-0.19) were obtained by Zimmermann et al. (2011) when fitting the modified Gompertz model to growth data of Neosartorya fischeri in pineapple juice. Galati et al. (2011) noted a slightly wider range of $R^{2}(0.96-1.00)$ for primary models based on the modified Gompertz equation describing growth of Aspergillus parasiticus on irradiated flint maize. High precision in kinetic parameter estimation with the use of the Gompertz equation was also attained by Tremarin et al. (2017) when applying it to Byssochlamys fulva growth in agar-added apple juices $\left(R^{2}=0.95-1.00\right)$. The values of the coefficients specified in the study are comparable with those presented by other researchers; however, the advantage of the presented results over the previously published stems from the much higher complexity of the modelled system.

The estimated values of lag phase duration prolonged with a decrease in water activity in grain and with a decrease in storage temperature. This trend is consistent with the results of other researchers (Aldars-García et al. 2017; Galati et al. 2011; Vindeløv and Arneborg 2002; Wawrzyniak et al. 2013; Zimmermann et al. 2011). The comparison of the estimated $\tau_{\text {lag }}$ duration with the maximum number of days, for which the OTA concentration in barley ecosystems was lower than the legislative limits of 3 and $5 \mathrm{mg} \mathrm{kg}^{-1}$ for cereal products for direct human consumption and unprocessed cereals, respectively (EC 2002, 2004, 2005, 2006, 2012), showed that in all cases, the estimated $\tau_{\text {lag }}$ was shorter than the time, after which the admissible limits of OTA was exceeded (Table 3) (Wawrzyniak et al. 2018a). Hence, the values of estimated $\tau_{\mathrm{lag}}$ may be used as the critical points to determine the safe period, at which grain should be subjected to preservation processes.

The increase in water activity and storage temperature was accompanied by the increase in the maximum growth rate of $\log (\mathrm{CFU})$ of moulds. The highest values of the estimated $\mu_{\max }$
Table 2 Estimated values of biological parameters of the modified Gompertz equation (Eq. (5)) determined for each set of storage conditions, and indices of the primary models goodness-offit to experimental data related to fungal development $(\log (\mathrm{CFU}))$ in barley grain with water activity $a_{\mathrm{w}}=0.78-0.96$ stored at $12-$ $30{ }^{\circ} \mathrm{C}$

\begin{tabular}{llllrlll}
\hline$T\left({ }^{\circ} \mathrm{C}\right)$ & $a_{\mathrm{w}}$ & $\log \mathrm{CFU}_{\mathrm{s}}\left(\log \left(\mathrm{cfu} \mathrm{g}^{-1}\right)\right)$ & $\mu_{\max }\left(\log \left(\mathrm{cfu} \mathrm{g}^{-1}\right) \mathrm{d}^{-1}\right)$ & $\tau_{\text {lag }}(\mathrm{d})$ & $R^{2}$ & $p$ & RMSE \\
\hline 12 & 0.89 & 6.8 & 0.08 & 14.3 & 0.995 & $<0.001$ & 0.061 \\
& 0.96 & 7.2 & 0.19 & 8.9 & 0.997 & $<0.001$ & 0.080 \\
18 & 0.85 & 6.2 & 0.13 & 13.5 & 0.998 & $<0.001$ & 0.051 \\
& 0.95 & 7.3 & 0.21 & 4.8 & 0.998 & $<0.001$ & 0.071 \\
24 & 0.81 & 6.2 & 0.15 & 17.8 & 0.987 & $<0.001$ & 0.131 \\
& 0.91 & 7.0 & 0.26 & 2.3 & 0.993 & $<0.001$ & 0.100 \\
& 0.93 & 7.5 & 0.28 & 1.4 & 0.984 & $<0.001$ & 0.155 \\
30 & 0.78 & 5.9 & 0.12 & 14.3 & 0.992 & $<0.001$ & 0.071 \\
& 0.80 & 6.4 & 0.22 & 9.6 & 0.993 & $<0.001$ & 0.080 \\
& 0.92 & 7.5 & 0.33 & 1.6 & 0.985 & $<0.001$ & 0.134 \\
\hline
\end{tabular}

$\log \left(C F U_{s}\right)$ the population level at the stationary phase, $p$ the test probability value at the significance level $\alpha=$ $0.05, R^{2}$ coefficient of determination, $R M S E$ root mean square error, $\mu_{\max }$ maximum growth rate in $\log (\mathrm{CFU}), \tau_{\text {lag }}$ lag phase duration 
Table 3 The duration of the lag phase of mould growth $\left(\tau_{\text {lag }}\right)$ in barley grain with water activity $a_{\mathrm{w}}=0.78-0.96$ stored at $12-30{ }^{\circ} \mathrm{C}$ estimated by the primary models and storage time adopted from Wawrzyniak et al. (2018a), after which binding limits of ochratoxin A (OTA) have been exceeded

\begin{tabular}{lllll}
\hline$T\left({ }^{\circ} \mathrm{C}\right)$ & $a_{\mathrm{w}}$ & $\tau_{\text {lag }}(\mathrm{d})$ & $\tau_{\text {OTA<3 }}(\mathrm{d})$ & $\tau_{\text {OTA<5 }}(\mathrm{d})$ \\
\hline 12 & 0.89 & 14.3 & 15 & 48 \\
& 0.96 & 8.9 & 9 & 12 \\
18 & 0.85 & 13.5 & 18 & 24 \\
& 0.95 & 4.8 & 6 & 12 \\
24 & 0.81 & 17.8 & $-{ }^{\mathrm{a}}$ & $-{ }^{\mathrm{a}}$ \\
& 0.91 & 2.3 & 4 & 8 \\
& 0.93 & 1.4 & 4 & 8 \\
30 & 0.78 & 14.3 & 16 & 32 \\
& 0.80 & 9.6 & 12 & 16 \\
& 0.92 & 1.6 & 4 & 6
\end{tabular}

${ }^{\text {a }}$ Admissible levels of OTA were not exceeded during 60-day of grain storage

were obtained in barley with $a_{\mathrm{w}}=0.92$ stored at $30{ }^{\circ} \mathrm{C}$ and $a_{\mathrm{w}}=$ 0.93 stored at $24{ }^{\circ} \mathrm{C}$ (Table 2). When studying the maximum growth rate of A. parasiticus in maize, Galati et al. (2011) also concluded that due to the high growth rate of fungi, grain stored at $30{ }^{\circ} \mathrm{C}$ is particularly vulnerable to mould contamination. In our study, the value of $\mu_{\max }$ evaluated in a bulk of barley with $a_{\mathrm{w}}=0.89$ stored at $12^{\circ} \mathrm{C}$ was approximately 4 times lower than the highest estimated value of $\mu_{\max }$. In turn, the $\mu_{\max }$ in grain with a lower $a_{\mathrm{w}}$, but stored at higher temperatures $\left(a_{\mathrm{w}}=0.78\right.$ 0.81 at $24-30{ }^{\circ} \mathrm{C}$ and $a_{\mathrm{w}}=0.85$ at $18^{\circ} \mathrm{C}$ ), slowed down about 2-3 times in comparison with the highest value of the $\mu_{\max }$.

The maximum levels of estimated $\log (\mathrm{CFU})$ of moulds at the stationary phase $\left(\log \left(\mathrm{CFU}_{\mathrm{s}}\right)\right)$ varied depending on $T$ and $a_{\mathrm{W}}$ in grain and fell within the range of 5.9-7.5 $\log \left(\mathrm{cfu} \mathrm{g}^{-1}\right)$. The obtained values of $\log \left(\mathrm{CFU}_{\mathrm{s}}\right)$ were close to the experimental results $\left(6.0-8.0 \log \left(\mathrm{cfu} \mathrm{g}^{-1}\right)\right.$ (Wawrzyniak et al. 2018a)).

\section{Overall Predictive Model of Mould Growth as a Function of Temperature and Water Activity}

There are numerous studies that describe the growth of microorganisms as a function of a single environmental factor, e.g. temperature (Gil et al. 2017; Robazza et al. 2017) or $a_{\mathrm{w}}$ (Patriarca et al. 2001; Zimmermann et al. 2011). Research works modelling the impact of both temperature and water availability on the kinetic parameters of the primary model were also undertaken. Tremarin et al. (2017) modelled the influence of temperature and soluble solids on the radial growth of $B$. fulva in agar-added apple juice. In turn, Galati et al. (2011) investigated the effect of temperature and water availability on growth of $A$. parasiticus on irradiated flint maize. Nevertheless, these studies usually investigated mould growth of a single strain on specially prepared food matrices (disinfected or solidified with agar). Bearing these facts in mind, in this study, the modelling approach was developed to estimate the expansion of total fungal population in the mass of stored barley grain. The considered barley ecosystems were treated holistically as a complex dynamic system of live organisms (grain, contaminants and microorganisms colonising it), in which fungal development depends on internal relationships, storage conditions and time. Therefore, when formulating the overall predictive model of mould growth, the biological parameters of the primary models (i.e. $\left.\mu_{\max }, \log \left(\mathrm{CFU}_{\mathrm{s}}\right), \tau_{\text {lag }}\right)$ were expressed as a function of environmental factors that most affect the fungal development, i.e. temperature and water availability in a bulk of grain. The values of coefficients, estimated during modelling, for the expressions describing the dependence of the model kinetic parameters on $T$ and $a_{\mathrm{w}}$ in grain and the results of their statistical assessment are presented in Table 4 . All estimated coefficients were statistically significant $(p<0.05)$.

Figure $1 \mathrm{a}-\mathrm{d}$ show comparisons between values of $\log (\mathrm{CFU})$ predicted with the $\mathrm{OPM}_{\mathrm{MG}}$ and the experimental data. Through their visual analysis, it can be noticed that the elaborated predictive model of mould growth fitted well to the experimental data. The differences between experimental and predicted levels of the fungal population observed at the beginning of the storage time results from the fact that during modelling, independently on storage conditions, the initial mould level $\left(\log \left(\mathrm{CFU}_{0}\right)\right)$ was assumed on the same level of $4.4 \log \left(\mathrm{cfu} \mathrm{g}^{-1}\right)$ being the average value of initial mould population of all storage experiments and reflecting the fungi

Table 4 The values of coefficients $\left(s_{i}, m_{i}, l_{i}\right)$ for the expressions describing the influence of temperature and water activity in barley grain on biological parameters $\left(\tau_{\text {lag }}, \mu_{\max }, \log \left(\mathrm{CFU}_{\mathrm{s}}\right)\right)$ of the overall predictive model of mould growth $\mathrm{OPM}_{\mathrm{MG}}$

\begin{tabular}{lrlcr}
\hline Coefficient & Estimate & Standard error & $t$-value & \multicolumn{1}{l}{$p$} \\
\hline $\log \left(\mathrm{CFU}_{\mathrm{s}}\right)=s_{0}+s_{1} \times t+s_{2} \times a_{\mathrm{w}}$ & & & \\
$s_{1}$ & 0.034 & 0.008 & 4.298 & 0.0036 \\
$s_{2}$ & 10.38 & 0.849 & 12.23 & $<0.0001$ \\
$s_{0}$ & -3.108 & 0.855 & -3.633 & 0.0084 \\
$\mu_{\max }=m_{0}+m_{1} \times t+m_{2} \times \mathrm{a}_{w}$ & & & \\
$m_{1}$ & 0.011 & 0.001 & 8.155 & 0.0001 \\
$m_{2}$ & 1.194 & 0.146 & 8.163 & 0.0001 \\
$m_{0}$ & -1.106 & 0.147 & -7.503 & 0.0001 \\
$\tau_{\text {lag }}=l_{0}+l_{1} \times t+l_{2} \times a_{\mathrm{w}}$ & & & \\
$l_{1}$ & -0.677 & 0.113 & -5.986 & 0.0005 \\
$l_{2}$ & -101.5 & 12.01 & -8.454 & 0.0001 \\
$l_{0}$ & 113.2 & 12.10 & 9.357 & $<0.0001$ \\
\hline
\end{tabular}

$p$ the test probability value at the significance level $\alpha=0.05$ 


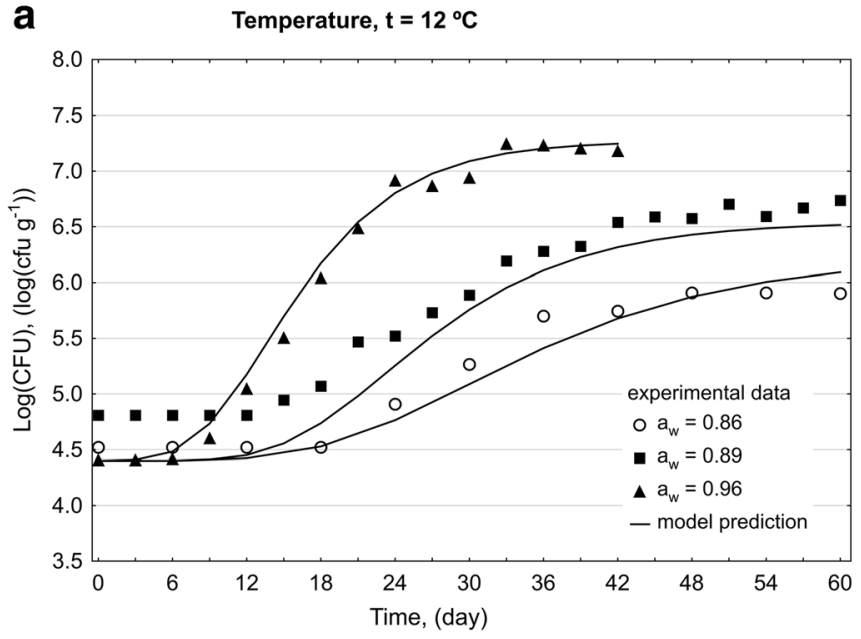

C

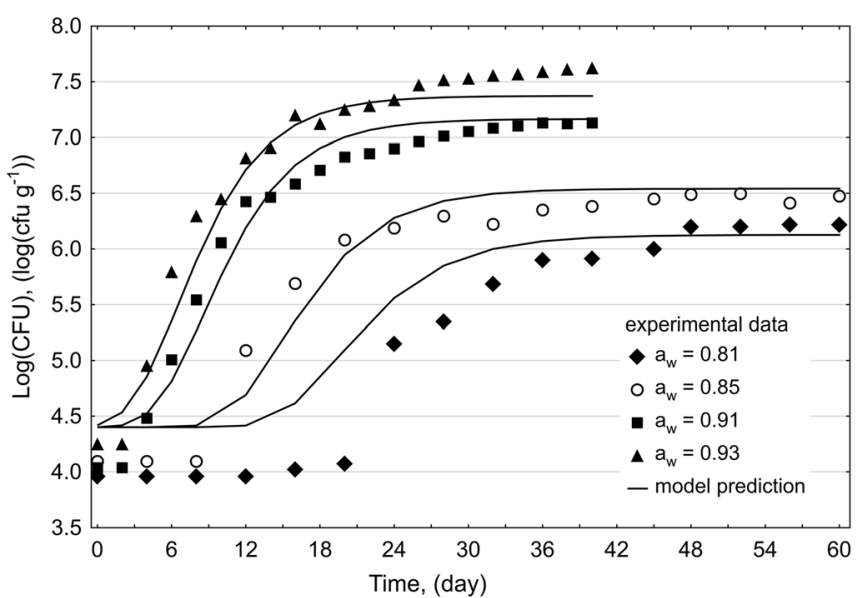

Fig. 1 Graphical presentation of the overall predictive model of mould growth validation. Plots of the fungal population level $(\log (\mathrm{CFU}))$ in bulks of barley grain with water activity $a_{\mathrm{w}}=0.78-0.96$ stored at a

population level characterizing grain ripening and harvested in years rich in precipitation (Akk et al. 2013).

Te Giffel and Zwietering (1999) indicated that the reason for a lesser accuracy of models may have miscellaneous sources such as the experimental error, natural variability, model inaccuracy or additional relevant factors influencing growth not included in the models. Therefore, as it was emphasized by Garcia et al. (2009) validation of models is crucial for their application in food safety management. In this study, the formulated $\mathrm{OPM}_{\mathrm{MG}}$ was subjected to a two-step evaluation (internal and external validation) in order to verify whether it is sufficiently suitable for practical use. The sets of storage conditions applied for model internal and external validation are presented in Table 1. Figure $2 \mathrm{a}$ and $\mathrm{b}$ depict the graphical relations between fungal population levels obtained during the experiments and the $\mathrm{OPM}_{\mathrm{MG}}$ predictions. The distribution of the points on the graphs indicated good agreement between the observed and predicted values of $\log (\mathrm{CFU})$ of moulds across the range of applied storage conditions for both b

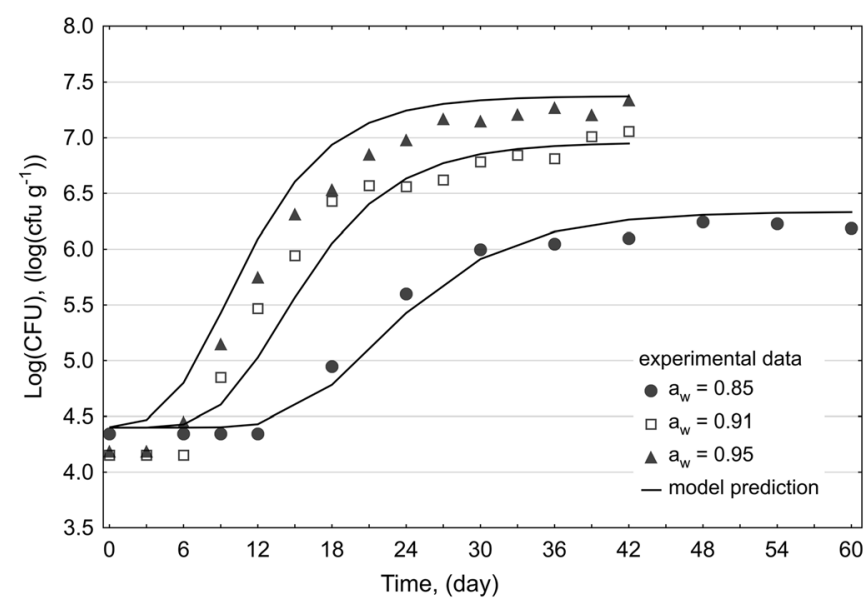

d

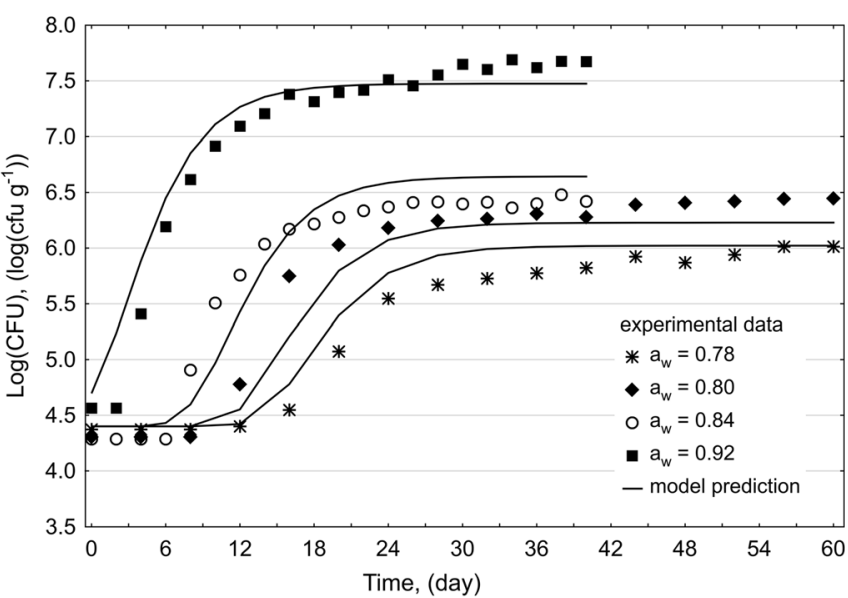

$12{ }^{\circ} \mathrm{C}$, b $18{ }^{\circ} \mathrm{C}$, c $24{ }^{\circ} \mathrm{C}$, d $30^{\circ} \mathrm{C}$ versus time. The continuous line represent the predictive model responses; the filled and empty points represent experimental and validation data $(\log (\mathrm{CFU}))$, respectively

validation methods. The prediction range of $95 \%$ in the graph correlating observed data and model estimates in the internal validation (Fig. 2a) shows that for a total number of 174 points, only 7 points (4.0\%) fall slightly outside the $95 \%$ prediction region. In the external validation (Fig. 2b) for a total amount of 63 points, only 2 points (3.2\%) fall outside the $95 \%$ prediction range.

The results of internal and external validations based on criteria recommended for predictive models by Te Giffel and Zwietering (1999) also showed good convergence between model estimates and experimental data. The validation indicators calculated to assess prediction quality of the $\mathrm{OPM}_{\mathrm{MG}}$ are presented in Table 5. The coefficient of determination $\left(R^{2}\right)$ in both validation approaches were within the range of 0.95 0.96 indicating high goodness of model fit over a wide range of $\log (\mathrm{CFU})$. The values of the root mean square error (RMSE), obtained for both internal and external validation (Table 5) showed that the $\mathrm{OPM}_{\mathrm{MG}}$ produces good predictions of growth data. The bias and accuracy factors were used as 

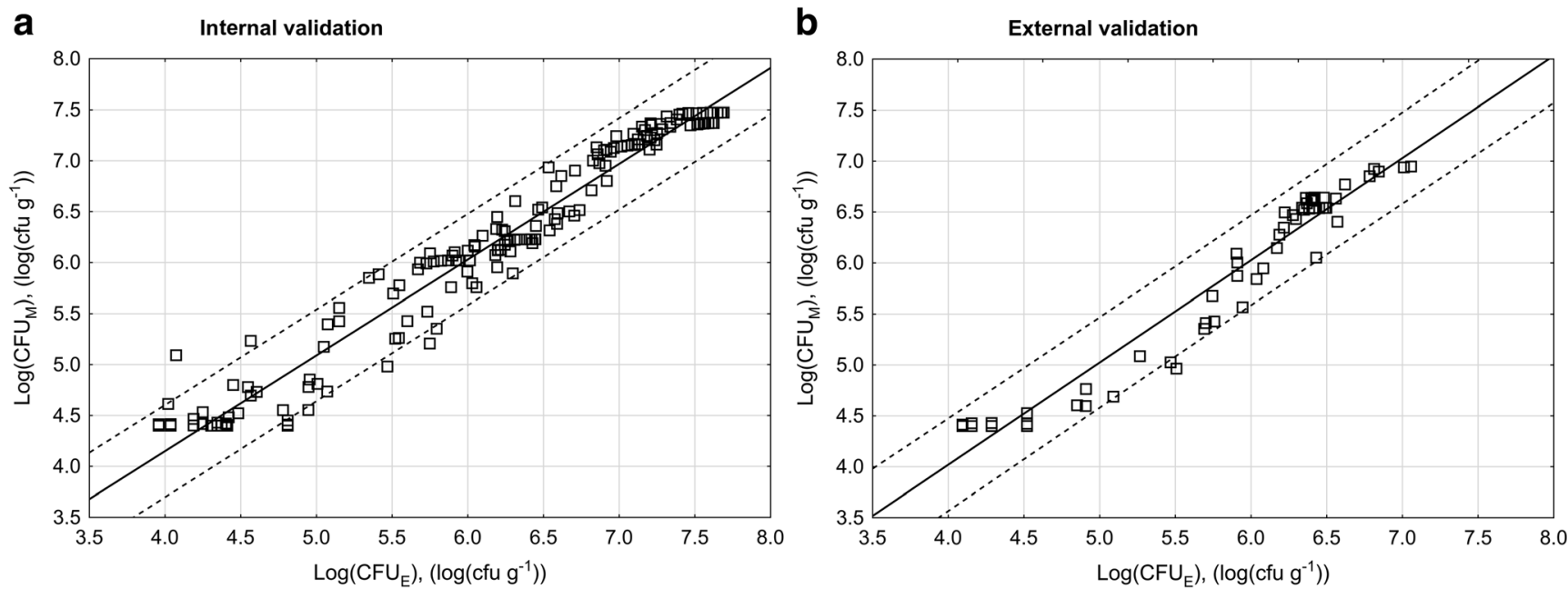

Fig. 2 Comparison of fungal population levels predicted with the model $\left(\log \left(C F U_{M}\right)\right)$ and the experimental data of fungal growth $\left(\log \left(C F U_{E}\right)\right)$, adopted from Wawrzyniak et al. (2018a), $\mathbf{a}$ internal validation and $\mathbf{b}$ external validation

further indicators for the quality of the model. These factors provide an objective information of model performance and are not based on the deviation between the observed and mean response, but test the hypothesis that the model under evaluation predicts the true mean (Te Giffel and Zwietering 1999). The values of $\mathrm{B}_{\mathrm{f}}$ obtained for the $\mathrm{OPM}_{\mathrm{MG}}$ as a result of internal and external validation are given in Table 5. Bae et al. (2012) indicated that the range of bias, for which the model can be considered as good, is $0.90-1.05$. The same authors reported that models with a bias in the range of $0.70-0.90$ or $1.06-1.15$ can be considered sufficient, whilst a bias of less than 0.70 or greater than 1.15 indicates a model which cannot be accepted. In the study, the values of $B_{\mathrm{f}} \mathrm{ob}-$ tained in both model validation methods qualified the $\mathrm{OPM}_{\mathrm{MG}}$ in the class of "good" models (Table 5). The $B_{\mathrm{f}}$ value a bit higher than 1 indicates on a "fail safe" model. It means that in general, the application of the predictive model developed in the study is safe, as it predicts slightly higher levels of fungal population than the actual one. As it was emphasised by Tremarin et al. (2017), such overestimation is not limitative and allows to avoid risky situations, since if the model is used to predict quality degradation, it would predict higher-quality degradation than the one that actually occurred. As the bias factor provides no indication of the average accuracy of estimates (under- and over-predictions tend to cancel out), the overall distance between the estimated and experimental values of fungal population was determined using the accuracy factor (Te Giffel and Zwietering 1999). The calculated values of $A_{\mathrm{f}}$ in the internal and external validations mean that on average, the predictions of the model deviated from observations by $3.4 \%$ and $3.5 \%$, respectively (Table 5 ). The recorded values of bias and accuracy factors are comparable with results of other studies. Samapundo et al. (2005) modelling the effect of water activity and temperature on the radial growth of Fusarium verticilliodes and Fusarium proliferatum on irradiated corn obtained the $B_{\mathrm{f}}$ from the range of 0.978 to 1.002 , whilst the $A_{\mathrm{f}}$ ranged from 1.098 to 1.122 . The study on the radial growth of $A$. flavus and $A$. parasiticus in irradiated black peppercorns using different kinetic models had $B_{\mathrm{f}}$ of 0.912 1.026 and $A_{\mathrm{f}}$ of $0.974-1.107$ (Yogendrarajah et al. 2016). The values of the calculated statistical indicators showed the high precision and accuracy of the model produced in this study, whilst the fact that the model was elaborated for a more complex system is its advantage over those published so far. Summarizing, the produced overall predictive model of mould growth predicted satisfactorily mould growth in a mass of barley grain throughout storage time. It can be used as a tool for predicting the extent of fungal contamination and the risk of mycotoxin appearance in barley grain during storage. Model forecasts can be particularly helpful in selecting an appropriate postharvest preservation method of freshly harvested grain (e.g. long-term and mild near-ambient drying or
Table 5 Validation indices for the performance of the overall predictive model of fungal growth in barley grain with water activity $a_{\mathrm{w}}=0.78-0.96$ stored at $12-$ $30{ }^{\circ} \mathrm{C}$

\begin{tabular}{llllllll}
\hline Type of verification & $N$ & $R^{2}$ & $t$ & $p$ & RMSE & $B_{\mathrm{f}}$ & $A_{\mathrm{f}}$ \\
\hline Internal & 174 & 0.956 & 60.86 & $<0.001$ & 0.243 & 1.006 & 1.034 \\
External & 63 & 0.947 & 33.03 & $<0.001$ & 0.234 & 1.004 & 1.035 \\
\hline
\end{tabular}

$A_{\mathrm{f}}$ accuracy factor, $B_{\mathrm{f}}$ bias factor, $N$ the number of validation points, $p$ the test probability value at the significance level $\alpha=0.05, R M S E$ root mean square error, $R^{2}$ coefficient of determination, $t$ test $t$ value 
relatively quick drying at higher temperature), which would allow to maintain its safety and high technological quality.

\section{Conclusions}

Due to deterioration of the quality of manufactured products and possible negative economic effects resulting from the activity of undesirable microorganisms, the microbiological state of cereal grain is of major importance to the food industry. One of the best ways to enhance the safety and nutritive value of stored grain is to develop predictive tools that estimate the dynamics of fungal growth (and thus the risk of mycotoxin formation) at an early stage of their activity. The study showed that the predictive model of total mould growth in a mass of barley grain, formulated on the basis of the modified Gompertz equation containing storage parameters affecting the fungal development, exhibits high accuracy and produces satisfactory prediction of the fungal population levels. The obtained model is able to predict the fungal grain contamination in a bulk of barley ecosystems stored in a wide range of temperature and humidity conditions based on easy measurable online parameters, e.g. temperature and intergranular relative humidity in a mass of grain. The results of the study indicate that the model may be applied as a useful decision support tool to develop innovative postharvest strategies and to improve management systems dedicated to grain preserved and stored in a bulk.

Funding This work was partially supported by the Polish Ministry of Science and Higher Education, Republic of Poland, grant number (N N313 209938).

\section{Compliance with Ethical Standards}

Conflict of Interest The author declares that there is no conflict of interest.

Open Access This article is licensed under a Creative Commons Attribution 4.0 International License, which permits use, sharing, adaptation, distribution and reproduction in any medium or format, as long as you give appropriate credit to the original author(s) and the source, provide a link to the Creative Commons licence, and indicate if changes were made. The images or other third party material in this article are included in the article's Creative Commons licence, unless indicated otherwise in a credit line to the material. If material is not included in the article's Creative Commons licence and your intended use is not permitted by statutory regulation or exceeds the permitted use, you will need to obtain permission directly from the copyright holder. To view a copy of this licence, visit http://creativecommons.org/licenses/by/4.0/.

\section{References}

Akk, E., Lõiveke, H., Edesi, L., Kütt, M. L., Lauringson, E., \& Kastanje, V. (2013). Formation of the abundance of microfungi on the barley grain grown as pure and mixed crops in central and North Estonia. Estonian Journal of Ecology, 62(4), 265-275. https://doi.org/10. 3176/eco.2013.4.03.

Aldars-García, L., Sanchis, V., Ramos, A. J., \& Marín, S. (2017). Single vs multiple-spore inoculum effect on growth kinetic parameters and modeled probabilities of growth and aflatoxin B1 production of Aspergillus flavus on pistachio extract agar. International Journal of Food Microbiology, 243, 28-35. https://doi.org/10.1016/j. ijfoodmicro.2016.11.026.

Bae, Y. M., Kim, B. R., Lee, S. Y., Cha, M. H., Park, K. H., Chung, M. S., \& Ryu, K. (2012). Growth and predictive model of Bacillus cereus on blanched spinach with or without seasoning at various temperatures. Food Science and Biotechnology, 21(2), 503-508. https://doi.org/10.1007/s10068-012-0064-7.

Bullerman, L. B., \& Bianchini, A. (2007). Stability of mycotoxins during food processing. International Journal of Food Microbiology, 119(1-2), 140-146. https://doi.org/10.1016/j.ijfoodmicro.2007.07. 035.

Cabañes, F. J., Bragulat, M. R., \& Castellá, G. (2010). Ochratoxin A producing species in the genus Penicillium. Toxins, 2(5), 11111120. https://doi.org/10.3390/toxins2051111.

Cairns-Fuller, V., Aldred, D., \& Magan, N. (2005). Water, temperature and gas composition interactions affect growth and ochratoxin A production by isolates of Penicillium verrucosum on wheat grain. Journal of Applied Microbiology, 99(5), 1215-1221. https://doi.org/ 10.1111/j.1365-2672.2005.02695.x.

Char, C. D., Guerrero, S. N., \& Alzamora, S. M. (2010). Mild thermal process combined with vanillin plus citral to help shorten the inactivation time for Listeria innocua in orange juice. Food and Bioprocess Technology, 3(5), 752-761. https://doi.org/10.1007/ s11947-008-0155-x.

Commission regulation (EC) 123/2005. Official Journal of the European Union. (2005). Amending regulation (EC) 466/2001 setting maximum levels for ochratoxin A in certain food stuffs. L25/3-5.

Commission regulation (EC) 1881/2006. Official Journal of the European Union. (2006). Commission regulation setting maximum levels for certain contaminants in foodstuffs.

Commission regulation (EC) 472/2002. Official Journal of the European Communities European Commission. (2002). Amending Regulation (EC) 466/2001 setting maximum levels for certain contaminants in foodstuff. L75/18-20.

Commission regulation (EC) 594/2012. Official Journal of the European Union. (2012). Amending regulation (EC) 1881/2006 as regards the maximum levels of the contaminants ochratoxin A, non-dioxin - like PCBs and melamine in foodstuffs. L176/43-45.

Commission regulation (EC) 683/2004. Official Journal of the European Union. (2004). Amending Regulation (EC) 466/2001 as regards aflatoxins and ochratoxin $\mathrm{A}$ in foods for infants and young children. L106/13-15.

Dantigny, P. (2016). Relevant issues in predictive mycology. Current Opinion in Food Science, 11, 29-33. https://doi.org/10.1016/j.cofs. 2016.08.011.

Galati, S., Giannuzzi, L., \& Giner, S. A. (2011). Modelling the effect of temperature and water activity on the growth of Aspergillus parasiticus on irradiated Argentinian flint maize. Journal of Stored Products Research, 47(1), 1-7. https://doi.org/10.1016/j.jspr.2010. 06.004 .

Gancarz, M., Wawrzyniak, J., Gawrysiak-Witulska, M., Wiącek, D., Nawrocka, A., Tadla, M., \& Rusinek, R. (2017). Application of electronic nose with MOS sensors to prediction of rapeseed quality. Measurement: Journal of the International Measurement Confederation, 103, 227-234. https://doi.org/10.1016/j. measurement.2017.02.042.

Garcia, D., Ramos, A. J., Sanchis, V., \& Marín, S. (2009). Predicting mycotoxins in foods: A review. Food Microbiology, 26(8), 757769. https://doi.org/10.1016/j.fm.2009.05.014. 
Gawrysiak-Witulska, M., Wawrzyniak, J., Ryniecki, A., \& Perkowski, J. (2008). Relationship of ergosterol content and fungal contamination and assessment of technological quality of malting barley preserved in a metal silo using the near-ambient method. Journal of Stored Products Research, 44(4), 360-365. https://doi.org/10.1016/j.jspr. 2008.03.007.

Gil, M. M., Miller, F. A., Brandão, T. R. S., \& Silva, C. L. M. (2017). Mathematical models for prediction of temperature effects on kinetic parameters of microorganisms' inactivation: Tools for model comparison and adequacy in data fitting. Food and Bioprocess Technology, 10(12), 2208-2225. https://doi.org/10.1007/s11947017-1989-x.

Gupta, S., Cox, S., Rajauria, G., Jaiswal, A. K., \& Abu-Ghannam, N. (2012). Growth inhibition of common food spoilage and pathogenic microorganisms in the presence of Brown seaweed extracts. Food and Bioprocess Technology, 5(5), 1907-1916. https://doi.org/10. 1007/s11947-010-0502-6.

Jacxsens, L., Yogendrarajaha, P., \& De Meulenaer, B. (2016). Risk assessment of mycotoxins and predictive mycology in Sri Lankan spices: Chilli and pepper. Procedia Food Science, 6, 326-330. https://doi.org/10.1016/j.profoo.2016.02.065.

Joint FAO/WHO Expert Committee on Food Additives (JECFA). (2002). Safety evaluation of certain food additives and contaminants. In Prepared by the 59th meeting of the JECFA. Geneva: Switzerland. World Health Organization https://apps.who.int/iris/handle/10665/ 42622.

Kochiieru, Y., Mankeviciene, A., Janaviciene, S., Jonaviciene, A., \& Ceseviciene, J. (2019). The influence of milling and sifting processes on deoxynivalenol distribution in whole-wheat flour and its products. World Mycotoxin Journal, 12(2), 133-140. https://doi.org/10. 3920/WMJ2018.2404.

Lindblad, M., Johnsson, P., Jonsson, N., Lindqvist, R., \& Olsen, M. (2004). Predicting noncompliant levels of ochratoxin A in cereal grain from Penicillium verrucosum counts. Journal of Applied Microbiology, 97(3), 609-616. https://doi.org/10.1111/j.13652672.2004.02332.x.

Liplap, P., Toussaint, V., Toivonen, P., Vigneault, C., Boutin, J., \& Raghavan, G. S. V. (2014). Effect of hyperbaric pressure treatment on the growth and physiology of Bacteria that cause decay in fruit and vegetables. Food and Bioprocess Technology, 7(8), 2267-2280. https://doi.org/10.1007/s11947-013-1197-2.

Lund, F., \& Frisvad, J. C. (2003). Penicillium verrucosum in wheat and barley indicates presence of ochratoxin A. Journal of Applied Microbiology, 95(5), 1117-1123. https://doi.org/10.1046/j.13652672.2003.02076.x.

Magan, N. (2006). Mycotoxin contamination of food in Europe: Early detection and prevention strategies. Mycopathologia, 162(3), 245253. https://doi.org/10.1007/s1 1046-006-0057-2.

Magan, N., \& Aldred, D. (2007). Post-harvest control strategies: Minimizing mycotoxins in the food chain. International Journal of Food Microbiology, 119(1-2), 131-139. https://doi.org/10.1016/j. ijfoodmicro.2007.07.034.

Magan, N., Hope, R., Cairns, V., \& Aldred, D. (2003). Post-harvest fungal ecology: Impact of fungal growth and mycotoxin accumulation in stored grain. European Journal of Plant Pathology, 109(7), 723-730. https://doi.org/10.1023/A:1026082425177.

Mankevičienè, A., Semaškienè, R., Dabkevičius, Z., Kochiieru, Y., Janavičienè, S., \& Jonavičienė, A. (2019). Do black dots on wheat grains have an impact on deoxynivalenol accumulation? Zemdirbyste, 106(3), 249-256. https://doi.org/10.13080/z-a.2019. 106.032 .

Marín, S., Colom, C., Sanchis, V., \& Ramos, A. J. (2009). Modelling of growth of aflatoxigenic $A$. flavus isolates from red chilli powder as a function of water availability. International Journal of Food Microbiology, 128(3), 491-496. https://doi.org/10.1016/j. ijfoodmicro.2008.10.020.
Medina, A., Akbar, A., Baazeem, A., Rodriguez, A., \& Magan, N. (2017). Climate change, food security and mycotoxins: Do we know enough? Fungal Biology Reviews, 31(3), 143-154. https://doi.org/ 10.1016/j.fbr.2017.04.002.

Mylona, K., \& Magan, N. (2011). Fusarium langsethiae : Storage environment in fluences dry matter losses and T2 and HT-2 toxin contamination of oats. Journal of Stored Products Research, 47(4), 321-327. https://doi.org/10.1016/j.jspr.2011.05.002.

Orina, I., Manley, M., \& Williams, P. J. (2017). Non-destructive techniques for the detection of fungal infection in cereal grains. Food research international (Ottawa, Ont.), 100(Pt 1), 74-86. https://doi. org/10.1016/j.foodres.2017.07.069.

Panagou, E. Z., Chelonas, S., Chatzipavlidis, I., \& Nychas, G. J. E. (2010). Modelling the effect of temperature and water activity on the growth rate and growth/no growth interface of Byssochlamys fulva and Byssochlamys nivea. Food Microbiology, 27(5), 618627. https://doi.org/10.1016/j.fm.2010.02.005.

Pardo, E., Marín, S., Solsona, A., Sanchis, V., \& Ramos, A. J. (2004). Modeling of germination and growth of ochratoxigenic isolates of Aspergillus ochraceus as affected by water activity and temperature on a barley-based medium. Food Microbiology, 21(3), 267-274. https://doi.org/10.1016/j.fm.2003.09.001.

Patriarca, A., Vaamonde, G., Fernandez, V., \& Comerio, R. (2001). Influence of water activity and temperature on the growth of Wallemia sebi: Application of a predictive model. International Journal of Food Microbiology, 68(1-2), 61-67. https://doi.org/10. 1016/S0168-1605(01)00470-6.

Pitt, J. I. (1987). Penicillium viridicatum, Penicillium verrucosum, and production of ochratoxin A. Applied and Environmental Microbiology, 53(2), 266-269. https://doi.org/10.1128/aem.53.2. 266-269.1987.

Robazza, W. d. S., Teleken, J. T., Galvão, A. C., Miorelli, S., \& Stolf, D. O. (2017). Application of a model based on the central limit theorem to predict growth of Pseudomonas spp. in fish meat. Food and Bioprocess Technology, 10(9), 1685-1694. https://doi.org/10. 1007/s11947-017-1939-7.

Rusinek, R., Gancarz, M., Krekora, M., \& Nawrocka, A. (2019). A novel method for generation of a fingerprint using electronic nose on the example of rapeseed spoilage. Journal of Food Science, 84(1), 5158. https://doi.org/10.1111/1750-3841.14400.

Ryniecki, A., Gawrysiak-Witulska, M., \& Wawrzyniak, J. (2007). Correlation for the automatic identification of drying endpoint in near-ambient dryers: Application to malting barley. Biosystems Engineering, 98(4), 437-445. https://doi.org/10.1016/j. biosystemseng.2007.09.014.

Samapundo, S., Devlieghere, F., De Meulenaer, B., Geeraerd, A. H., Van Impe, J. F., \& Debevere, J. M. (2005). Predictive modelling of the individual and combined effect of water activity and temperature on the radial growth of Fusarium verticilliodes and F. proliferatum on corn. International Journal of Food Microbiology, 105(1), 35-52. https://doi.org/10.1016/j.ijfoodmicro.2005.06.007.

Saxena, J., Munimbazi, C., \& Bullerman, L. B. (2001). Relationship of mould count, ergosterol and ochratoxin A production. International Journal of Food Microbiology, 71(1), 29-34. https://doi.org/10. 1016/S0168-1605(01)00584-0.

Serment-Moreno, V., Fuentes, C., Barbosa-Cánovas, G., Torres, J. A., \& Welti-Chanes, J. (2015). Evaluation of high pressure processing kinetic models for microbial inactivation using standard statistical tools and information theory criteria, and the development of generic time-pressure functions for process design. Food and Bioprocess Technology, 8(6), 1244-1257. https://doi.org/10.1007/s11947-0151488-x.

Serment-Moreno, V., Torres, J. A., Fuentes, C., Ríos-Alejandro, J. G., Barbosa-Cánovas, G., \& Welti-Chanes, J. (2016). Limitations of the log-logistic model for the analysis of sigmoidal microbial inactivation data for high-pressure processing (HPP). Food and Bioprocess 
Technology, 9(5), 904-916. https://doi.org/10.1007/s11947-016$1677-2$.

Te Giffel, M. C., \& Zwietering, M. H. (1999). Validation of predictive models describing the growth of Listeria monocytogenes. International Journal of Food Microbiology, 46(2), 135-149. https://doi.org/10.1016/S0168-1605(98)00189-5.

Tremarin, A., Aragão, G. M. F., Salomão, B. C. M., Brandão, T. R. S., \& Silva, C. L. M. (2017). Modeling the soluble solids and storage temperature effects on Byssochlamys fulva growth in apple juices. Food and Bioprocess Technology, 10(4), 720-729. https://doi.org/ 10.1007/s11947-016-1854-3.

Valdivia-Nájar, C. G., Martín-Belloso, O., Giner-Seguí, J., \& SolivaFortuny, R. (2017). Modeling the inactivation of Listeria innocua and Escherichia coli in fresh-cut tomato treated with pulsed light. Food and Bioprocess Technology, 10(2), 266-274. https://doi.org/ 10.1007/s11947-016-1806-y.

Vindeløv, J., \& Arneborg, N. (2002). Effects of temperature, water activity, and syrup film composition on the growth of Wallemia sebi: Development and assessment of a model predicting growth lags in syrup agar and crystalline sugar. Applied and Environmental Microbiology, 68(4), 1652-1657. https://doi.org/10.1128/AEM.68. 4.1652-1657.2002.

Walther, B. A., \& Moore, J. L. (2005). The concepts of bias, precision and accuracy, and their use in testing the performance of species richness estimators, with a literature review of estimator performance. Ecography, 28(6), 815-829. https://doi.org/10.1111/j. 2005.0906-7590.04112.x.

Wang, Y., Yi, J., Yi, J., Dong, P., Hu, X., \& Liao, X. (2013). Influence of pressurization rate and mode on inactivation of natural microorganisms in purple sweet potato nectar by high hydrostatic pressure. Food and Bioprocess Technology, 6(6), 1570-1579. https://doi. org/10.1007/s11947-012-0897-3.

Wawrzyniak, J., \& Waśkiewicz, A. (2014). Ochratoxin A and citrinin production by Penicillium verrucosum on cereal solid substrates. Food Additives and Contaminants - Part A Chemistry, Analysis, Control, Exposure and Risk Assessment, 31(1), 139-148. https:// doi.org/10.1080/19440049.2013.861933.
Wawrzyniak, J., Ryniecki, A., \& Gawrysiak-Witulska, M. (2013). Kinetics of mould growth in the stored barley ecosystem contaminated with Aspergillus westerdijkiae, Penicillium viridicatum and Fusarium poae at $23-30{ }^{\circ} \mathrm{C}$. Journal of the Science of Food and Agriculture, 93(4), 895-901. https://doi.org/10.1002/jsfa.5820.

Wawrzyniak, J., Waśkiewicz, A., \& Ryniecki, A. (2018a). Evaluation of critical points of mould growth and mycotoxin production in the stored barley ecosystem with a hazardous initial microbiological state of grain. Journal of Stored Products Research, 77, 166-176. https://doi.org/10.1016/j.jspr.2018.04.008.

Wawrzyniak, J., Gawrysiak-Witulska, M., \& Ryniecki, A. (2018b). Management control points related to the lag phase of fungal growth in a stored rapeseed ecosystem. JAOCS, Journal of the American Oil Chemists' Society, 95(9), 1223-1235. https://doi.org/10.1002/aocs. 12130.

Yogendrarajah, P., Vermeulen, A., Jacxsens, L., Mavromichali, E., De Saeger, S., De Meulenaer, B., \& Devlieghere, F. (2016). Mycotoxin production and predictive modelling kinetics on the growth of Aspergillus flavus and Aspergillus parasiticus isolates in whole black peppercorns (Piper nigrum L). International Journal of Food Microbiology, 228, 44-57. https://doi.org/10.1016/j. ijfoodmicro.2016.03.015.

Zimmermann, M., Miorelli, S., Massaguer, P. R., \& Falcão Aragão, G. M. (2011). Modeling the influence of water activity and ascospore age on the growth of Neosartorya fischeri in pineapple juice. $L W T$ Food Science and Technology, 44(1), 239-243. https://doi.org/10. 1016/j.lwt.2010.06.034.

Zwietering, M. H., Jongenburger, I., Rombouts, F. M., \& Van't Riet, K. (1990). Modeling of the bacterial growth curve. Applied and Environmental Microbiology, 56(6), 1875-1881. https://doi.org/ 10.1128/aem.56.6.1875-1881.1990.

Publisher's Note Springer Nature remains neutral with regard to jurisdictional claims in published maps and institutional affiliations. 